\title{
Antimicrobial activity of Guava tree (Psidium Guajava) leaf extract and selected Commercial Antibiotics on Bacterial isolates from Kisubi Hospital.
}

\author{
Journal of Microbiology@S JHR-Africa. \\ David Serunjogia,1,2, Kizito Muwonge ${ }^{\text {b,3 }}$ \\ a Faculty of Health Sciences, Uganda Martyrs University, \\ Kampala, Uganda \\ b Department of Health Sciences, University of Kisubi, \\ Kisubi, Uganda
}

\begin{abstract}
Background:
Plant species such as the guava have been used in Uganda and elsewhere in the world to treat some of the medical conditions associated with bacteria, this is due to the increased number of drug resistant bacteria in the world. In this study, the antimicrobial activity of guava leaf extracts against some of the disease causing bacteria isolated from Kisubi hospital in Uganda is discussed.

Methods:

The guava leafs were collected from a plantation near Zika forest in Uganda $\left(0^{\circ} 7^{\prime} 27^{\prime \prime} \mathrm{N} 32^{\circ} 31^{\prime} 32^{\prime \prime} \mathrm{E} /\right.$ $0.12417^{\circ} \mathrm{N} 32.52556^{\circ} \mathrm{E} / 0.12417 ; 32.52556$ ) and samples were put in a bag and transferred to the university laboratory where they were identified. The extracts were obtained by maceration using distilled water, 30\%, 50\% and $70 \%$ methanol as the extraction solvents. Antimicrobial susceptibility testing was conducted using the disc diffusion method.

Results:

Gram negative Escherichia coli was sensitive to the plant extract, and so was the synthetic commercial drugs such as trimethoprim-sulfamethozole, ciprofloxacin and Gentamicin. Pseudomonas aeruginosa was resistant to all drugs. Streptococcus pneumonia and Staphylococcus aureus were all sensitive to the plant extracts with measurable inhibition zones.

Conclusion:

The Guava tree leaf crude extracts have antimicrobial activity against drug resistant bacteria. More studies should be carried out to know the potency and the concentration of the plant origin extracts.
\end{abstract}

\section{Introduction:}

The guava tree is an evergreen small tree. The guava leaves are 2 to 6 inches long and 1 to 2 inches wide, aromatic when crushed, and appear dull-green with stiff but coriaceous with pronounced veins (Endeguelea et al., 2018). There are bioactive components in the guava leaf that can fight against pathogens, regulate blood glucose levels, and can even aid in weight loss (Burkill et al., 1997). The guava Psidium

\footnotetext{
${ }^{1}$ Corresponding author.

2E-mail: serunjogidavid16@gmail.com

3E-mail: kizitomm@gmail.com
} 
Guajava $L$ is a phytotherapeutic plant used in fork medicine that is believed to have active components that treat infections that are caused by pathogenic bacteria (Bipul et al., 2013). Several fruits and fruit extracts, as well as arrowroot tea extract (Kim et al., 2004) and caffeine (Ibrahim et al.,2006), have been found to exhibit anti-microbial activities against E. coli 0157:H7(Rinky, 2016). This suggests that plants which manifest relatively high levels of antimicrobial action may be a source of compounds that can be used to inhibit the growth of pathogens (Bipul, 2013).

Antimicrobial compounds as biological compounds can inhibit the growth of bacteria. Guava leaves are commonly used as a traditional medicine to cure diarrhea and thrush. Fruits have also been used traditionally to cure diarrhea. According to Subashini et al., (2007), Guava leaves contain the active chemical compounds saponins, flavonoids, tannins, eugenol, and triterpenoids. Polyphenolic compounds dominating guava leaves are flavonoids (>1.4) and tannins. Polyphenolic compounds are antibacterial compounds that can inhibit the growth of bacteria (Ncube, 2008).

Worldwide, there is a growing concern over antimicrobial resistance (AMR) which is currently estimated to account for more than 700,000 deaths per year and it's expected to take 10 million lives by 2050 (O'Neill et al.,2016). Due to this increase in the number of drug-resistant bacteria, in Africa, the use of plant origin medicine as an alternative to treat infections is on a rise. In Uganda so many herbal products are on market, little is documented about how the active phytochemicals in these products are extracted and which part of the plant contains the active phytochemicals that are used, this possesses a great risk to the would-be alternative source to synthetic drugs and more studies are needed to address this. This study aims to investigate the antimicrobial activity of the Guava leaf extract and selected commercial synthetic drugs on the market against bacteria isolates from Kisubi Hospital, in Uganda.

\section{Methods}

\section{MATERIALS AND METHODS}

\section{1}

\subsubsection{Data Collection Methods}

\section{Instruments}

The tools used in the study included analytical scale, a blender, sieves, desiccators, Petri dishes, magnetic stirrer, pipettes, filter paper, aluminum foil, vortex mixer, incubator, centrifuge, and platform shaker, sieve, stop clock, cock borer and labeling pencil.

\section{Materials}

Materials used in the study included the guava leaves, distilled water, technical ethanol of $30 \%, 50 \%$, and 70\%, blood agar, Muller Hinton Agar, and MacConkey Agar.

\subsubsection{Preparation of the plant extract}

The guava leafs were collected from a plantation near Zika forest $\left(0^{\circ} 7^{\prime} 27^{\prime \prime} \mathrm{N} 32^{\circ} 31^{\prime} 32^{\prime \prime} \mathrm{E} / 0.12417^{\circ} \mathrm{N}\right.$ $\left.32.52556^{\circ} \mathrm{E} / 0.12417 ; 32.52556\right)$ and samples were put in a bag and transferred to the university laboratory where it was identified. The guava leaves were washed using tap water and allowed to dry, weighted and its average weights were recorded as follows;

The average wet mass $=2.5 \mathrm{~g}$ each leaf.

The guava leaves were left to dry at $29^{\circ} \mathrm{C}$ for 7 days and the average weight was recorded as the dry mass

The average dry mass $=0.83 \mathrm{~g}$ each leaf.

\section{Methods of extraction}

Maceration method of extraction was used to obtain the guava extract. The leaves were crushed into a powder using a blender and $20 \mathrm{~g}$ of the powder was added into different labeled beakers containing $100 \mathrm{mls}$ of distilled water and $100 \mathrm{mls}$ of increasing concentration of methanol from $30 \%, 50 \%$ and $70 \%$. 
The powder was mixed with the solvents using a vortex for 2 minutes and the flasks were covered with aluminum foil and left to stand at the working bench for 3 days at $29^{\circ} \mathrm{C}$.

The flasks were shaken vigorously after the 3 days of soaking in solvent then the mixtures were transferred to $4 \mathrm{~mL}$ tubes and centrifuged for $10 \mathrm{~min}$ at $4,000 \mathrm{rpm}$ at $29^{\circ} \mathrm{C}$. The supernatant was collected and stored at $4^{\circ} \mathrm{C}$.

Antimicrobial activity of the guava extracts

4.1.1 Preparation of the discs

Antimicrobial susceptibility testing was done using the disc diffusion method. The discs were made by punching holes in filter papers using a punching machine. These were autoclaved at $121^{\circ} \mathrm{C}$. The discs were then soaked in the different extracts for 24 hours at $4^{\circ} \mathrm{C}$.

\subsubsection{Isolation and identification of bacteria}

Bacterial isolates were collected from door handles, patient bedding and other areas using sterile swabs. They were transferred to the microbiology laboratory and cultured. Identification of the bacteria was done using characteristics of colony morphology, Gram staining and biochemical tests.

\section{Media preparation}

\subsubsection{Media preparation and inoculation}

Peptone water was prepared following the manufacturer's instructions (OXOID LTD, Basingstoke, Hampshire, England), dispensed in test tubes, and plugged with cotton wool and aluminum foil. The media were autoclaved at $121^{\circ} \mathrm{C}(15 \mathrm{psi})$ for 15 minutes, and allowed to cool, and kept at $4^{\circ} \mathrm{C}$ until needed for use in seven days. The media were allowed to rise to room temperature before use. MacConkey culture media was prepared by dissolving 44.4g of the powder in 1.0 liter of distilled water. This procedure followed the manufacturer's instructions (Mast Group Ltd., Merseyside, U.K.). The prepared media was autoclaved at $121^{\circ} \mathrm{C}(15 \mathrm{psi})$ for 15 minutes, allowed to cool, and kept at $4^{\circ} \mathrm{C}$ until needed for use in seven days. The media were allowed to rise to room temperature before use. Sterility testing was done by incubating the media at $37^{\circ} \mathrm{C}$ overnight.

\subsubsection{Inoculation}

The bacterial growth in peptone water was adjusted to the $0.5 \mathrm{McFarland}$ standard solution using normal saline (Cheesbrough et al.,2006); a sterile cotton swab was dipped into the suspension, rotated several times, and pressed firmly on the inside wall of the tube above the fluid level removing excess inoculum (Bipul, 2013). The surface of the agar plate containing the sample was spread using a spreader rotating the plate to ensure an even distribution of inoculum. The plates were allowed to release the excess moisture in 3 to 4 minutes.

The soaked discs were picked from different extracts using a sterile pair of forceps, these were placed on agar plates bearing the organisms, and little pressure was exerted to ensure that the discs were firm onto the media. For each bacterial isolate, controls were maintained where pure solvents were used instead of the extract. The plates were sealed with parafilm, labeled, and placed in an incubator set to $37^{\circ} \mathrm{C}$ for 24 hours. Each plate was then examined for zones of inhibition. A ruler was used to measure the average diameter of each zone of inhibition.

\subsubsection{Measurement of the zones of inhibition}

A ruler was used to measure the clear zone of inhibition and this was done by taking measurements from one end of the inhibition zone to the other end.

Shows two zones of inhibition by the guava leaf extracts on different types of bacteria

The performance of Psidium guajava leaf extract was also compared with standard antibiotics in inhibiting bacterial growth. The antibiotics studied included ampicillin, chloramphenicol, ciprofloxacin, 


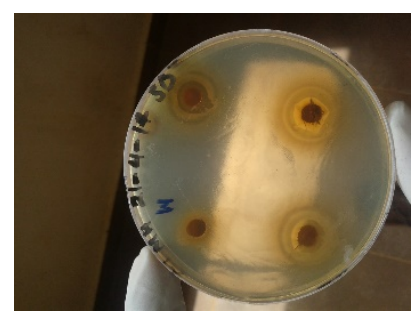

Figure 1. Shows two zones of inhibition by the guava leafextracts on different types of bacteria

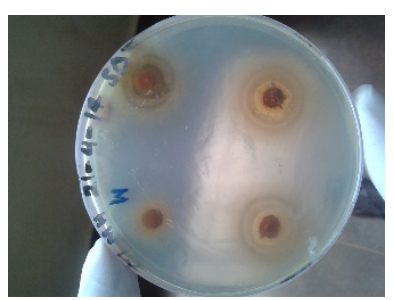

Figure 2. Shows two zones of inhibition by the guava leaf extracts on different types of bacteria

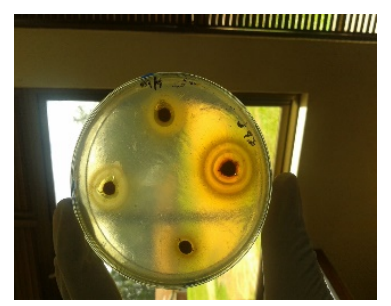

Figure 3. Shows two zones of inhibition by the guava leaf extracts on different types of bacteria

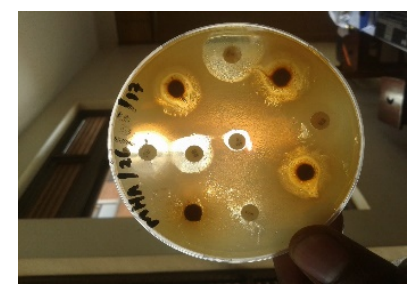

Figure 4. Shows the inhibition zones of both the plant extract and the selected antibiotic discs

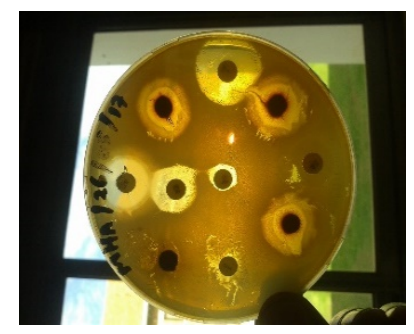

Figure 5. Shows the inhibition zones of both the plant extract and the selected antibiotic discs 


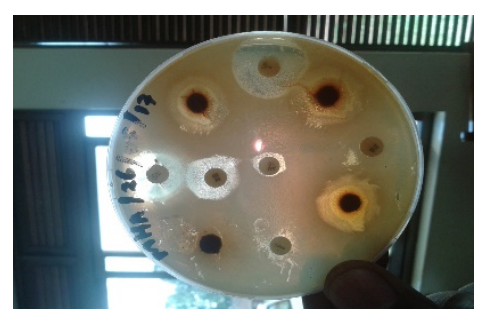

Figure 6. Shows the inhibition zones of both the plant extract and the selected antibiotic discs

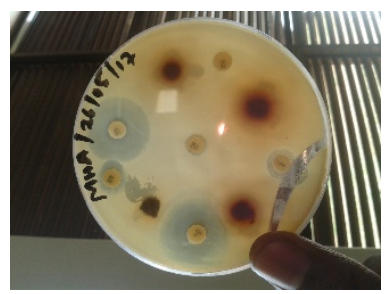

Figure 7. Shows the inhibition zones of both the plant extract and the selected antibiotic discs

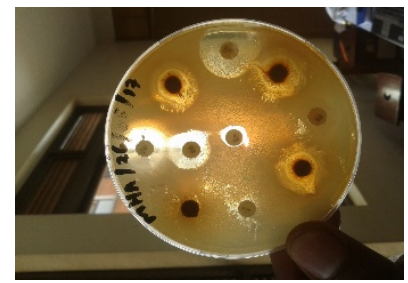

Figure 8. Shows the inhibition zones of both the plant extract and the selected antibiotic discs

gentamicin, nitrofurantoin, and trimethoprim-sulfamethoxazole. Escherichia coli and Staphylococcus aureus positively proven isolates were used to quality control Gram staining procedure.

\section{5 performance of the extracts in inhibiting bacterial growth}

5.1

\subsubsection{Effect of plant extract and selected drugs on Escherichia coli}

The discs obtained from the guava extract using water as the extraction medium showed no antimicrobial activity against the bacteria. However, the extract obtained using $30 \%$ methanol as the extraction medium showed the highest antimicrobial activity with an inhibition zone of $19.0 \mathrm{~mm}$, both the $50 \%$ and $70 \%$ concentration of methanol extract showed an inhibition zone of $15.0 \mathrm{~mm}$.

In comparison to the standard selected drugs, the bacteria were sensitive to gentamicin (CN10 $\mu \mathrm{g})$, ciprofloxacin (CIP5 $\mu \mathrm{g}$ ), and Trimethoprim-sulfamethoxazole (TS2 $\mu \mathrm{g}$ ) with zones of inhibition measuring $24 \mathrm{~mm}, 24 \mathrm{~mm}$, and $24 \mathrm{~mm}$ respectively. Escherichia coli was resistant to Nitrofurantoin (NI50 $\mu \mathrm{g})$ with $12 \mathrm{~mm}$ and Ampicillin (AM10 $\mu \mathrm{g}$ ) with a zone of $8 \mathrm{~mm}$. Two zones of bacteria inhibition were formed by Chloramphenicol ( $\mathrm{C} 5 \mathrm{O} \mu \mathrm{g})$ with, the first zone of inhibition measuring $11 \mathrm{~mm}$ (bacteria resistant) and the second inhibition zone measuring $23 \mathrm{~mm}$ (sensitive).

\subsubsection{Antimicrobial activity against Streptococcus pneumonia}

The Guava leaf extract of varying methanol concentrations of $30 \%, 50 \%$, and $70 \%$ inhibited the growth of streptococcus pneumonia with two zones of clearance measuring $14 \mathrm{~mm}, 16 \mathrm{~mm}$, and $13 \mathrm{~mm}$ in the $1 \mathrm{st}$ 
Table 1. Shows performance of the extracts in inhibiting bacterialgrowth

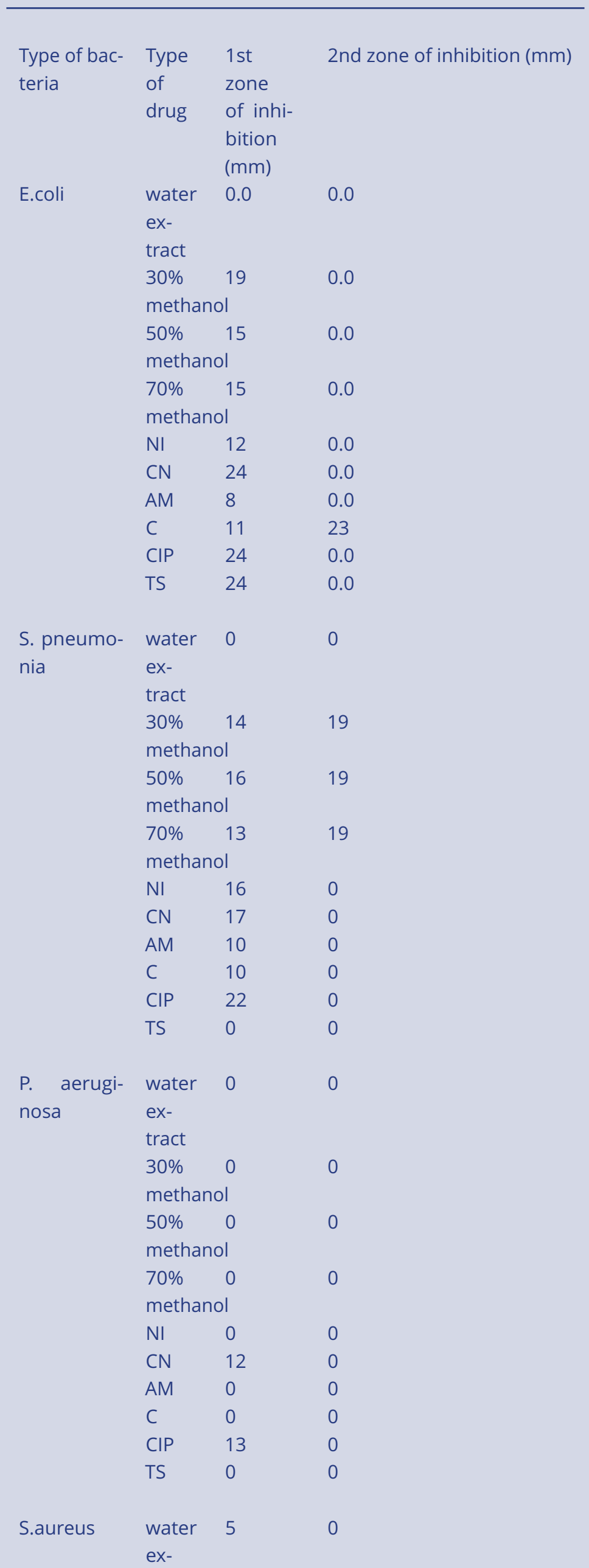




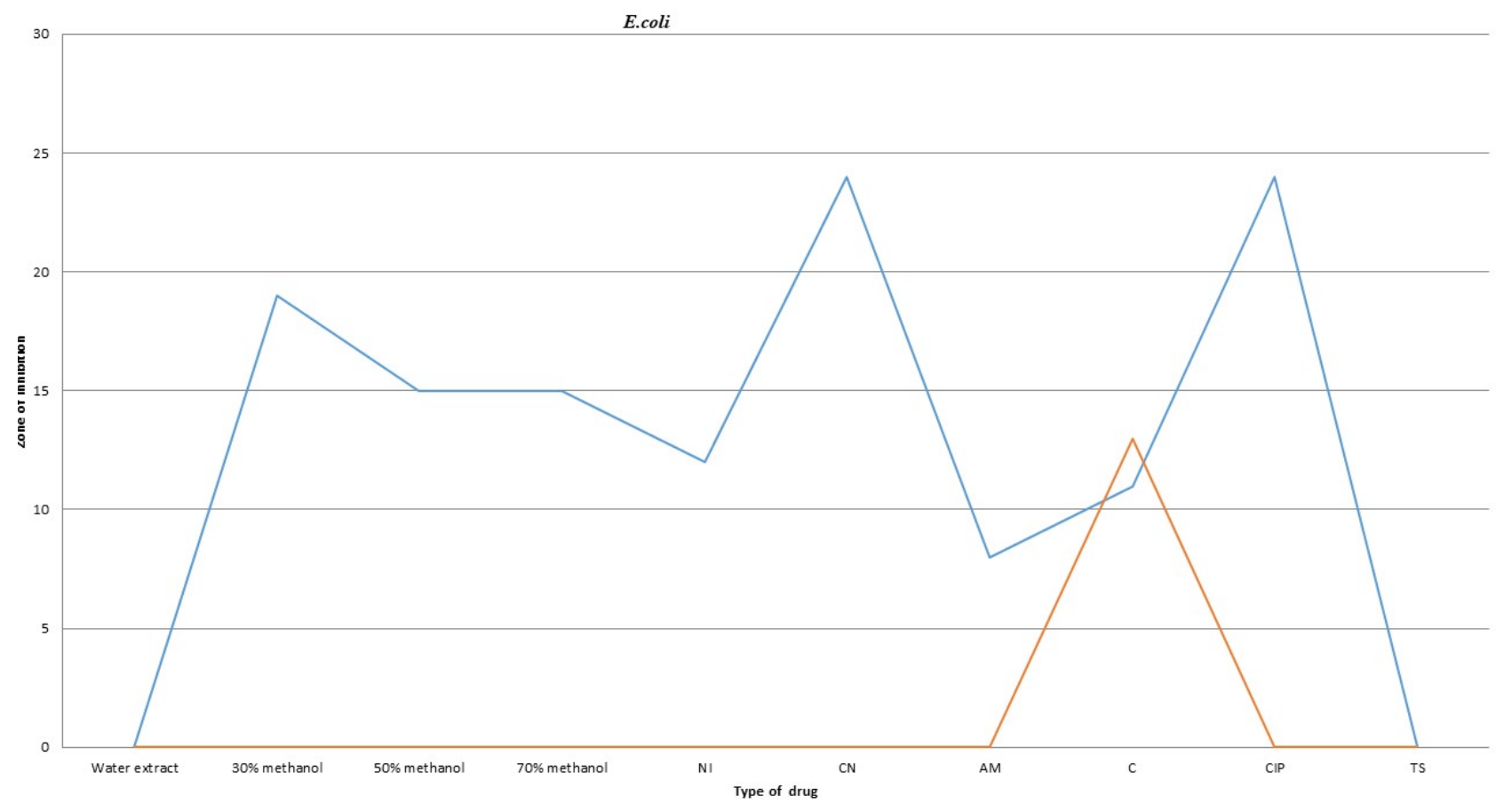

Chart 1. a line graph showing the first zone of inhibition

zone respectively. All the 2 nd zones of different methanol concentrations measured $19 \mathrm{~mm}$. The bacteria were resistant to the leaf extract from distilled water with no zone of clearance.

In comparison to the selected synthetic drugs, Streptococcus pneumoniae was susceptible to both Ciprofloxacin (CIP5 $\mu \mathrm{g}$ ) and Gentamicin (CN10 $\mu \mathrm{g}$ ) with an inhibition zone of $22.0 \mathrm{~mm}$ and $17.0 \mathrm{~mm}$ respectively. Nitrofurantoin ( $\mathrm{NI50} \mu \mathrm{g}$ ) effect on bacteria was intermediate with a zone of inhibition of 16.0

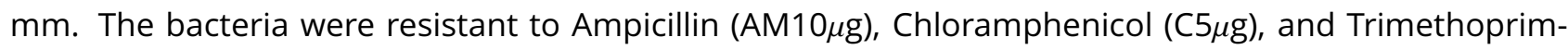
sulfamethoxazole (TS25 $\mu \mathrm{g})$.

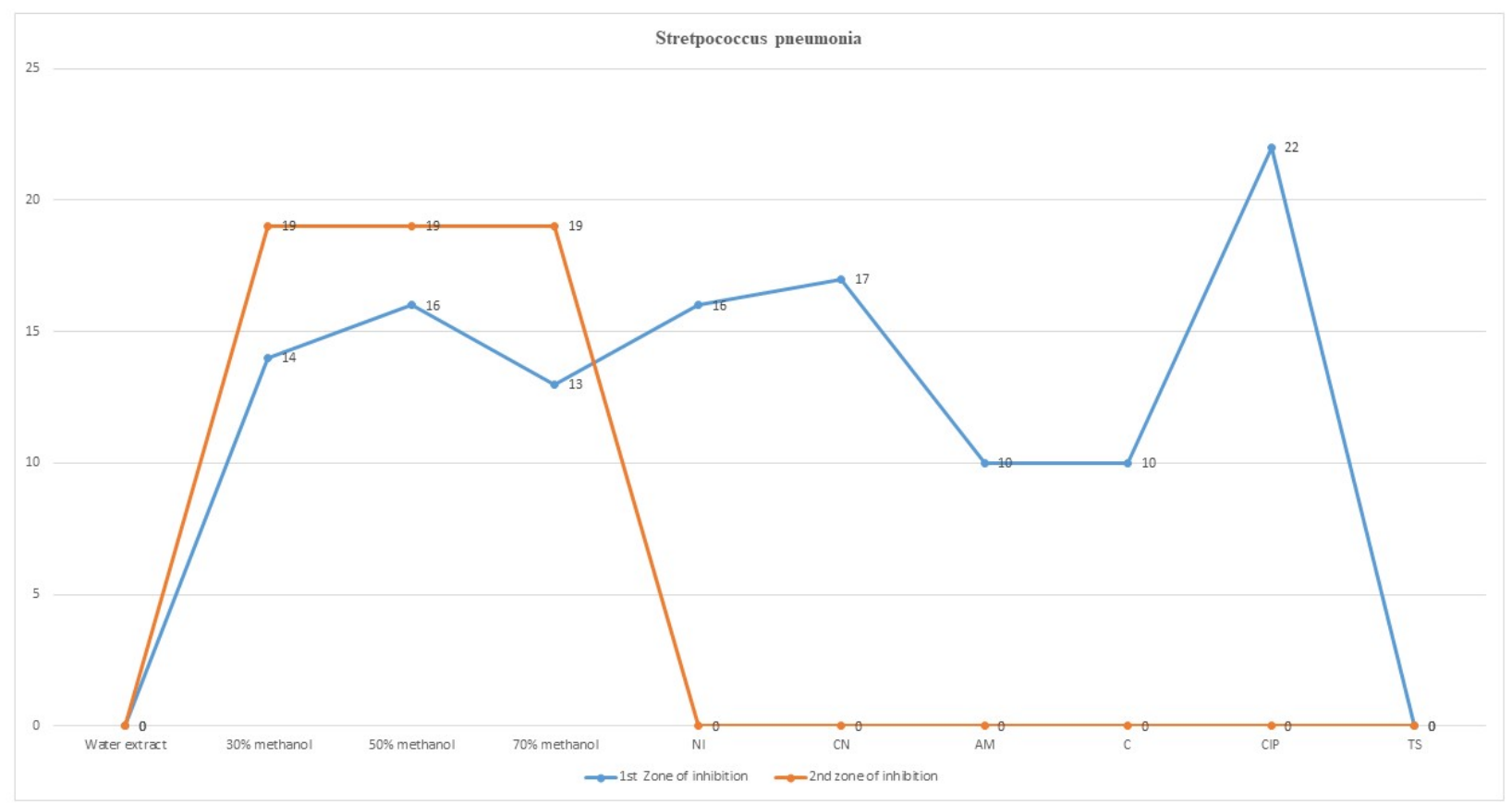

Chart 2. a line graph showing zones of inhibition 


\subsubsection{Antimicrobial activity against Pseudomonas aeruginosa}

The bacteria were resistant to all solvent extracts (water extract, 30\% methanol, 50\% methanol, and $70 \%$ methanol), and selected synthetic drugs. Only Ciprofloxacin (CIP5 $\mu \mathrm{g}$ ) and Gentamicin (CN10 $\mu \mathrm{g})$ in the synthetic drugs showed antimicrobial activity with inhibition zones measuring $13 \mathrm{~mm}$ and $12 \mathrm{~mm}$ respectively.

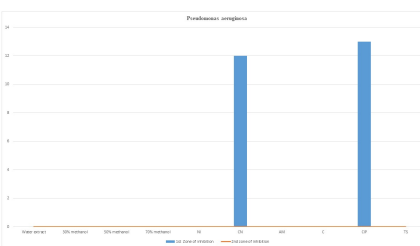

Chart 3. A combined bar and line graph (right) showing how Pseudomonas aeruginosa resisted the different antibiotics and the plant extract.

\subsubsection{Antimicrobial activity against Staphylococcus aureus}

The Guava extract from distilled water inhibited the growth of bacteria to a clearance zone measuring $5 \mathrm{~mm}$.

The guava leaf extract from the increasing concentration of methanol of 30\%, 50\%, and $70 \%$ inhibited the growth of bacteria with two zones of clearance around the discs measuring $7 \mathrm{~mm}$ for the disc of 30\%, $7 \mathrm{~mm}$ for the disc of $50 \%$, and $8 \mathrm{~mm}$ for the disc of $70 \%$ in the 1 st zone of clearance. The second zone of clearance measured $11 \mathrm{~mm}$ for $30 \%$ methanol, $11 \mathrm{~mm}$ for $50 \%$ methanol, and $9 \mathrm{~mm}$ for $70 \%$ methanol concentration.

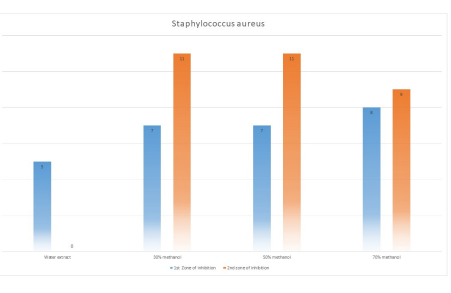

Chart 4. a bar graph: water extract did not show a $2^{\text {nd }}$ inhibition zone as compared to the rest.

\section{CONCLUSION AND DISCUSSION}

It is now evident that the discs obtained from the crude Guava leaf extracts which are commonly found in Uganda can inhibit the growth of bacteria. These crude extracts obtained using methanol of varying concentrations can inhibit the growth of most of the gram-positive and some gram-negative bacteria. The presence of inhibition zones around the discs that contained the crude extracts of the guava leaf shows that Staphylococcus aureus and Streptococcus Pneumoniae is sensitive to the crude extract and should be considered as a possible source of remedy against gram Positive bacterial infections.

It has been reported earlier by Bipul et al., (2013) that Gram-negative bacteria are usually more resistant to the plant-origin antimicrobials and even show no effect, compared to Gram-positive bacteria, a finding that is supported by these results due to the inability of the guava leaf extract to inhibit the growth of Pseudomonas aeruginosa. These findings also suggest that not all gram-negative bacteria maybe be resistant to plant origin antimicrobials as results from Escherichia coli Showed zones of inhibition. The resistance of some the Gram-negative bacteria could be attributed to its cell wall structure. Gram-negative bacteria have an effective permeability barrier, comprised of a thin lipopolysaccharide exterior membrane, which could restrict the penetration of the plant extract as compared to Gram-positive bacteria. 
Distilled water as an extraction solvent did well when extracting phytochemicals against gram-positive Staphylococcus aureus as compared to other bacteria such as Escherichia coli, Pseudomonas aeruginosa, and Streptococcus Pneumoniae which were resistant to the crude extract. Increasing the concentration of methanol did not yield a more potent extract against the bacteria, making the $30 \%$ methanol concentration a more suitable extraction solvent for the active phytochemicals.

It is unclear what caused the presence of two inhibition zones exhibited by some organism, this can be attributed to the effect of methanol used during the extraction. The unevaporated methanol in the extract could have diffused accounting for the 2 nd inhibition zone obtained, this line of discussion can be supported from the discs which were obtained from the water extract, these did not show the second zone of inhibition. However, the above hypothesis should be subjected to further research due to the presence of a 2nd inhibition zone measuring $13 \mathrm{~mm}$ showed by a commercial drug Chloramphenicol (C5 $\mu \mathrm{g})$ on Escherichia coli. This characteristic was not present on any other microorganisms. it could be possible that the second zone of inhibition was due to some degree of resistance by bacteria. In conclusion, more precise studies should be carried out to find out which particular phytochemical(s) (secondary metabolite) have the antimicrobial activity against gram-negative and gram-positive bacteria and how best can they be concentrated for accurate and precise application of the guava extract in the treatment of conditions associated with the infectious bacteria. Future studies should look out for the second zones of inhibition and provide a more detailed explanation.

\section{References:}

1. Amita P, Shalini T., (2013) "Concept of standardization, extraction and pre phytochemical screening strategies for herbal drugs."

2. Bipul Biswas, Kimberly Rogers, Fredrick McLaughlin, Dwayne Daniels, Anand Yadav, (2013) "Antimicrobial Activities of Leaf Extracts of Guava (Psidium guajava L.) on Two Gram-Negative and Gram-Positive Bacteria", International Journal of Microbiology, vol. 2013, Article ID 746165, 7 pages, 2013.

3. Burkillet H. M, (1997) "The Useful Plants of West Tropical Africa”, 2nd edition, 1997.

4. Cheesbrough M, (2006). District Laboratory practice in Tropical Countries. Cambridge University Press.

5. Clinical and Laboratory Standards Institute, (2009) “Performance standards for antimicrobial susceptibility testing," Nineteenth informational supplement M100-S19, Clinical and Laboratory Standards Institute, Wayne, Pa, USA.

6. Ibrahim S. A. , Salameh M. M., Phetsomphou, H. Yang, and Seo C. W., (2006) “Application of caffeine, 1,3,7-trimethylxanthine, to control Escherichia coli 0157:H7," Food Chemistry, pp. 645-650.

7. Kim. S and Fung D. Y. C. (2004), "Antibacterial effect of crude water-soluble arrowroot (Puerariae radix) tea extracts on food-borne pathogens in liquid medium," Letters in Applied Microbiology, pp. 319-325.

8. Kim. S and Fung D. Y. C., (2004) "Antibacterial effect of crude water-soluble arrowroot (Puerariae radix) tea extracts on food-borne pathogens in liquid medium," Letters in Applied Microbiology, pp. 319-325.

9. Ncube N. S., Afolayan A. J, and Okoh, (2008) "Assessment techniques of antimicrobial properties of natural compounds of plant origin: current methods and future trends," African Journal of Biotechnology, pp. 1797-1806.

10. Ncube N. S., Afolayan A. J., and Okoh A. I., (2008) "Assessment techniques of antimicrobial properties of natural compounds of plant origin: current methods and future trends," African Journal of Biotechnology, pp. 1797-1806

11. O'Neill J., (2006) “Tackling Drug-Resistant Infections Globally: Final Report and Recommendations”. (h ttp://amr-review.org/sites/default/files/160525_Final\%20paper_with\%20cover.pdf).

12. Rameshkumar K. B., George V., and Shiburaj, (2007) "Chemical constituents and antibacterial activity of the leaf oil of cinnamomum chemungianum Mohan et Henry," Journal of Essential Oil Research, pp. 98-100. 
13. Srinky b., Sheetal c., Pavan k. a., (2016) "Antimicrobial and phytochemical analysis of leaf extract of medicinal fruit plant". vol 9, issue 4.

14. Tamokou JD, Fosso MJA, Njouendou AJ, Ekom SE, Kengne IC., (2017) "Antibacterial activity of three Cameroonian medicinal plants traditionally used for the treatment of urinary tract infections and their synergistic effects with amoxicillin and serum". 